\title{
Study of the Effects of Magnesium Content on the Mechanical Properties of Aluminium 6063 Extrudates
}

\author{
N. Kodikara and G.I.P. De Silva
}

\begin{abstract}
This research study focussed on how the mechanical properties - hardness, strength and ductility - of aluminium 6063 T5 extrudates get improved when the magnesium content of the extrudates is increased. The average hardness, yield strength and the percentage elongation of the extrudates produced by Alumex (Pvt) Ltd were taken as the reference values. Magnesium content was varied in the standard range of $0.45-0.9 \mathrm{wt} \%$ by introducing calculated amounts of pure $\mathrm{Mg}$ ingot $(99.9 \% \mathrm{Mg})$. The hardness, yield strength and elongation of the samples which had different amounts of $\mathrm{Mg}$ in them were measured using a vickers hardness testing machine and a standard tensile testing machine. The experimental results obtained showed that the hardness and the yield strength of the samples increased and that their ductility decreased when their $\mathrm{Mg}$ contents were increased from $0.45 \%$ to $0.71 \%$. However, it was observed that there was a general reduction in the hardness and yield strength, and a drastic reduction in the elongation of the samples when the Mg content was increased beyond $0.71 \%$.
\end{abstract}

Keywords: $\quad$ Age hardening, Al 6063 T5, Hardness, Ductility, Yield strength

\section{Introduction}

Aluminium is the most abundantly present metal in the Earth's crust and about $8 \%$ of the Earth's solid surface by weight is aluminium [1]. Aluminium 6063 T5 is an artificially age hardened alloy that is extensively used in structural applications such as partitioning and in window and door frames, bars of varying cross sections and ladders. Its properties like light weight, resistance to corrosion, high strength and extrudability make it an excellent structural material. Furthermore, it is considered as an environmentally friendly material because in the production of aluminium extruded items, pure metal ingots and $30-50 \%$ of aluminium scraps are used.

Magnesium (0.45-0.9 wt\%) and silicon (0.2-0.6 $\mathrm{wt} \%)$ are the main alloying elements of aluminium 6063. T5 denotes the heat treatment process of cooling starting from hot working and ending with artificial age hardening. The use of aluminium 6063 extruded items is rapidly increasing, even though the properties such as strength and hardness are not up to the required levels in some of the items produced. Furthermore, because of their low strength, defects such as door and window frame deformation can occur (Figure 1).

The most important phenomenon related with aluminium 6063 alloy is precipitation hardening. $\mathrm{Mg}_{2} \mathrm{Si}$ precipitates formed in the matrix affect the three mechanical properties hardness, strength and ductility - by serving as a barrier for dislocation movement. The size, shape and distribution of the precipitates depend on the parameters of the heat treatment process and the chemical composition of the alloy. There are few reports [2, 12] which discuss the influence of the chemical composition on the yield strength.

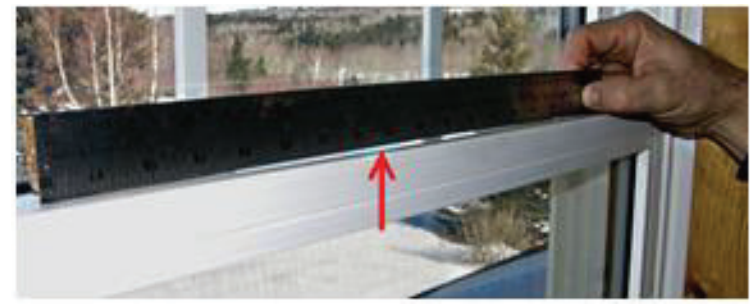

Figure 1 - Deformation in a Al 6063 door frame

This work focused first on studying the effect of $\mathrm{Mg}$ content on the hardness, yield strength and ductility of $\mathrm{Al} 6063$ alloy by varying it in the standard range $0.45-0.9 \mathrm{wt} \%$. The next stage of the work focused on studying the effect of other alloying elements, $\mathrm{Si}$ and $\mathrm{Cu}$, on the three mechanical properties.

The age hardening process which forms major precipitates such as $\beta^{\prime \prime}-\mathrm{Mg}_{5} \mathrm{Si}_{6}, \beta^{\prime}-\mathrm{Mg}_{1.8} \mathrm{Si}$

Mr. N. Kodikara, B.Sc. Eng. (Hons) (Moratuwa)

Email: navinish8915@gmail.com

Eng. (Dr.) G.I.P. De Silva, B.Sc. Eng. (Hons) (Moratuwa) M.Phil. (Moratuwa), Ph.D.(Kochi, Japan), C. Eng., MIE(SL) Senior lecturer in the Department of Materials Science and Engineering, University of Moratuwa.

Email:indikagip@uom.lk 
cuboid and $\beta-\mathrm{Mg}_{2} \mathrm{Si}$ as well as the precipitates, $\mathrm{Al}(\mathrm{MnFe}) \mathrm{Si}, \mathrm{MgAl}_{2} \mathrm{Si}_{2}$ etc., is the phenomenon that leads to the development of the mechanical properties [2]. Generally, in order to obtain the required mechanical properties, the size, shape and distribution of the particles can be changed by varying the chemical composition of the alloy.

\section{Methodology}

A laboratory scale induction furnace (IGBT 40) was used to melt the $\mathrm{Al} 6063$ alloy samples by heating them to the temperature range of $660{ }^{\circ} \mathrm{C}-680^{\circ} \mathrm{C}$ (Figure 2). During heating, the samples were kept in a graphite crucible which is inert with a higher thermal shock resistance. Graphite being a conductive material, crucibles made of graphite will be suitable for heating the samples. $\mathrm{Mg}$ content was varied in the standard range of $0.45-0.90 \mathrm{wt} \%$ by using a $\mathrm{Mg}$ ingot with $99.9 \% \mathrm{Mg}$.

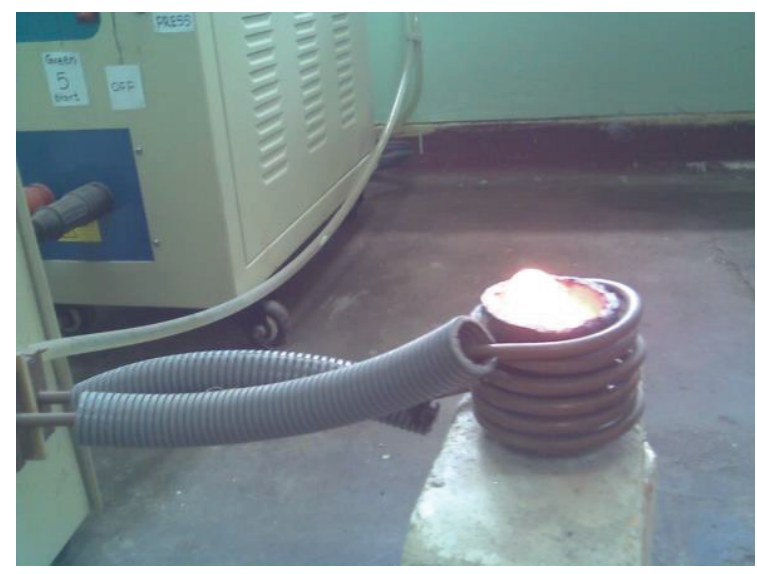

Figure 2 - Melting of Al 6063 Alloy using the induction furnace (IGBT 40)

liquid metal was poured into the cast iron mould (Figure 4) which was designed to get 3 tensile test specimens and one cylindrical shaped part for the vickers hardness test (Figure 5). An atomic absorption spectrometer was used for analysing the chemical composition of the cast samples. Atomic absorption spectroscopy is an analytical procedure for the quantitative determination of chemical elements using the absorption of optical radiation by free atoms in the gaseous state. Samples were subjected to a heat treatment process comprising solution treatment: keeping at $540^{\circ} \mathrm{C}$ for 3 hours, followed by age hardening treatment: keeping at $205^{\circ} \mathrm{C}$ for 2.5 hours and furnace cooling (Figure 3).

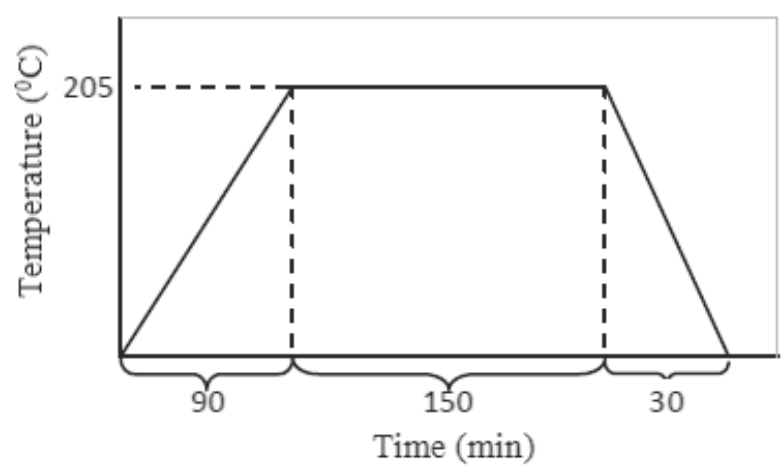

Figure 3 - Age hardening treatment applied to the samples

Tensile test using a universal tensile testing machine and in accordance with the ASTM E-8 standards was carried out on three standard test pieces prepared from each composition. Yield strength and percentage elongation of the samples were estimated using the stress-strain diagram obtained. The standard vickers hardness tester was used to measure the hardness as per ASTM E92 standards. The load applied was $10 \mathrm{~kg}$ and the indenter used had a diameter of $1 / 16^{\prime \prime}$. Three hardness measurements were taken for each composition to calculate the average hardness.

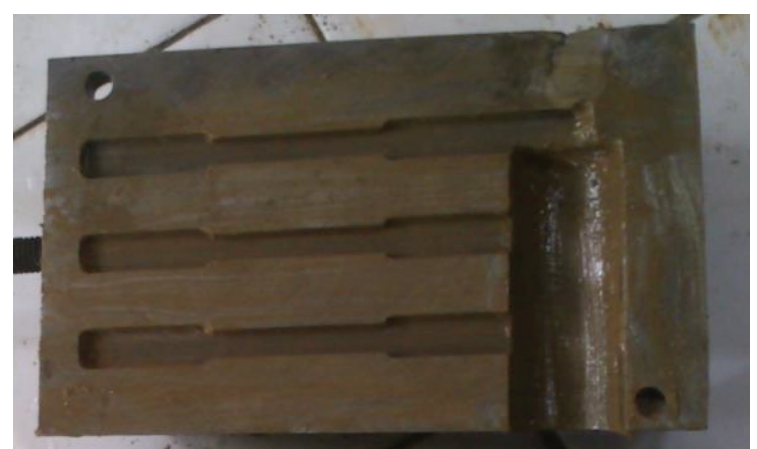

Figure 4 - Cast iron mould designed to prepare specimens for the tensile test and hardness test

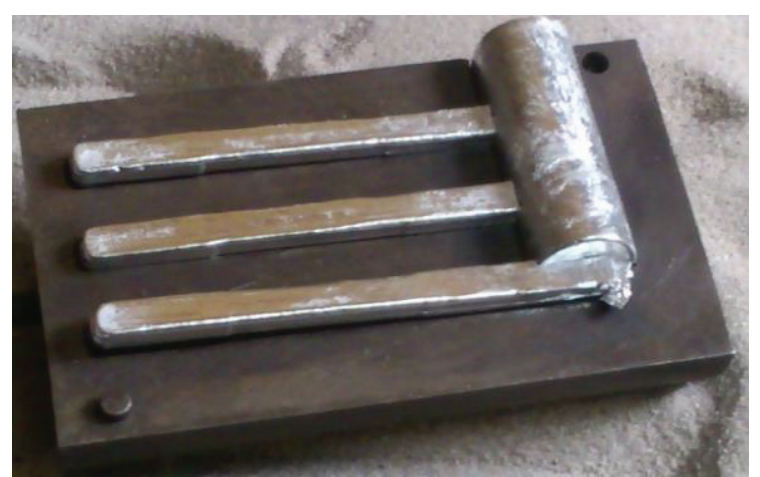

Figure 5 - Al 6063 casting comprising the specimens used in the tensile test and hardness test 


\section{Results and Discussion}

Samples prepared were of seven compositions containing different amounts of $\mathrm{Mg}$ (Table 1). The quantities of other alloying elements in the samples were kept almost constant.

Table 1 - Compositions of the Al 6063 samples

\begin{tabular}{|c|l|l|l|l|l|l|}
\hline Sample & $\mathrm{Al}$ & $\mathbf{M g}$ & $\mathrm{Si}$ & $\mathrm{Cu}$ & $\mathrm{Fe}$ & $\mathrm{Mn}$ \\
\hline 1 & 98.92 & $\mathbf{0 . 4 5}$ & 0.34 & 0.05 & 0.21 & 0.03 \\
\hline 2 & 98.82 & $\mathbf{0 . 5 6}$ & 0.35 & 0.04 & 0.21 & 0.02 \\
\hline 3 & 98.75 & $\mathbf{0 . 6 0}$ & 0.36 & 0.05 & 0.22 & 0.02 \\
\hline 4 & 98.73 & $\mathbf{0 . 6 4}$ & 0.34 & 0.05 & 0.21 & 0.03 \\
\hline 5 & 98.63 & $\mathbf{0 . 7 1}$ & 0.36 & 0.05 & 0.22 & 0.03 \\
\hline 6 & 98.58 & $\mathbf{0 . 7 9}$ & 0.35 & 0.04 & 0.21 & 0.03 \\
\hline 7 & 98.52 & $\mathbf{0 . 8 5}$ & 0.35 & 0.05 & 0.20 & 0.03 \\
\hline
\end{tabular}

Table 2 - Mg/Si Ratio (by weight) of the Al 6063 samples

\begin{tabular}{|c|c|c|c|}
\hline Sample & $\mathrm{Mg}$ & $\mathrm{Si}$ & $\mathrm{Mg} / \mathrm{Si}$ \\
\hline 1 & 0.45 & 0.34 & 1.32 \\
\hline 2 & 0.56 & 0.35 & 1.60 \\
\hline 3 & 0.60 & 0.36 & 1.66 \\
\hline 4 & 0.64 & 0.34 & 1.88 \\
\hline 5 & 0.71 & 0.36 & 1.97 \\
\hline 6 & 0.79 & 0.35 & 2.26 \\
\hline 7 & 0.85 & 0.35 & 2.43 \\
\hline
\end{tabular}

According to Figures 7 and 8, hardness and yield strength increase as the $\mathrm{Mg}$ content is increased up to $0.71 \%$ by weight and they start decreasing with any further increase in the $\mathrm{Mg}$ content. Moreover, the ductility of the samples also decreases as the $\mathrm{Mg}$ content is increased up to $0.71 \%$ and beyond this point, however, it will decrease at a higher rate (Figure 9).

Precipitate formation sequence during the age hardening process [2] is shown in Figure 6.

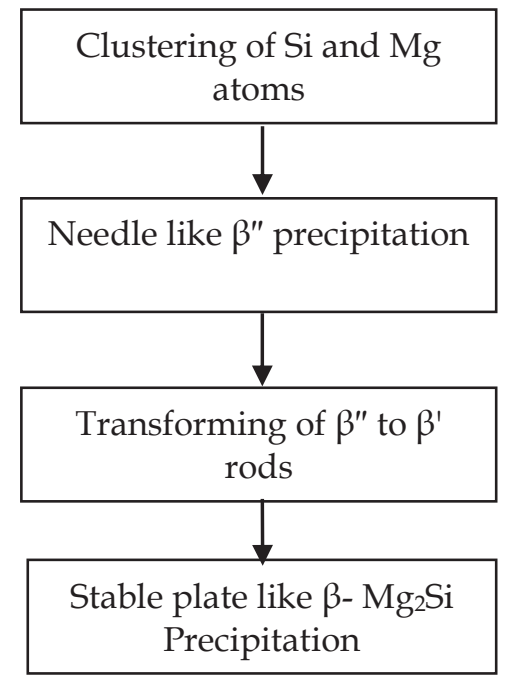

Figure 6 - Precipitate formation sequence during age hardening of Al 6063 Alloy
Age hardening temperature was set at $205{ }^{\circ} \mathrm{C}$ as $\beta-\mathrm{Mg}_{2} \mathrm{Si}$ precipitate forms and remains stable above $200{ }^{\circ} \mathrm{C}$ [2]. However, $\beta^{\prime \prime}-\mathrm{Mg}_{5} \mathrm{Si}_{6}$ and $\beta^{\prime}-$ $\mathrm{Mg}_{1.8} \mathrm{Si}$ which form between $125{ }^{\circ} \mathrm{C}-200{ }^{\circ} \mathrm{C}$ remain stable above $200{ }^{\circ} \mathrm{C}$ [3]. The $\mathrm{Mg} / \mathrm{Si}$ ratio by weight in $\beta^{\prime \prime}-\mathrm{Mg}_{5} \mathrm{Si}_{6}, \beta^{\prime}-\mathrm{Mg}_{1.8} \mathrm{Si}$ and cuboid $\beta-\mathrm{Mg}_{2} \mathrm{Si}$ can be considered as $0.72,1.56$ and 1.73 respectively. It is well known that hardness and strength increase towards the $\beta-\mathrm{Mg}_{2} \mathrm{Si}$ side in the above sequence [4]. Hardness and yield strength were increased up to the Mg content of $0.71 \%$ as $\mathrm{Mg} / \mathrm{Si}$ ratio was increased up to 1.97 and $\beta-\mathrm{Mg}_{2} \mathrm{Si}$ is formed

In the samples that had excess $\mathrm{Mg}$ contents, the number of $\mathrm{Mg}_{2} \mathrm{Si}$ precipitates significantly increased becoming larger in size [5]. The improvements in hardness and strength witnessed with the increased number and size of $\mathrm{Mg}_{2} \mathrm{Si}$ precipitates can be explained using the cutting through mechanism and Rowans bowing mechanism [6]. However, at a certain excess amount of $\mathrm{Mg}$, relatively coarse $\mathrm{Mg}_{2} \mathrm{Si}$ precipitate starts to form which is called the over-aged state. Highly stressed and concentrated areas are developed around these coarse plates leading micro cracks in the matrix-particle interface to form under plastic deformation (7). This is the obvious reason for the reduction of hardness and yield strength, and for the drastic reduction of elongation when the $\mathrm{Mg}$ content is increased beyond $0.71 \%$.

The Al 6063 samples prepared with a Mg content between $0.45-0.85 \%$ showed hardness, yield strength and percentage elongation in the ranges of $65-77 \mathrm{HV}, 195-220 \mathrm{MPa}$ and $10-13 \%$ respectively. Similarly, when the amounts of other alloying elements- $\mathrm{Si}, \mathrm{Mn}$ and $\mathrm{Cu}$ are varied, the ranges of variation of hardness, yield strength and percentage elongation may change. However, when the $\mathrm{Si}$ content is lowered below a certain level, the fluidity and hot tear resistance will also get reduced during the casting and extrusion processes [8]. Moreover, as the amounts of $\mathrm{Mg}$ and $\mathrm{Cu}$ are reduced below a certain level, corrosion resistance will also start to decrease $[9,10]$. Therefore, the varying of the contents of the alloying elements should be optimized to obtain the required combination of mechanical properties while preventing the degradation of other properties like fluidity and corrosion resistance. This work can be extended to develop a mathematical model to find the composition that best gives the required level of mechanical properties. 


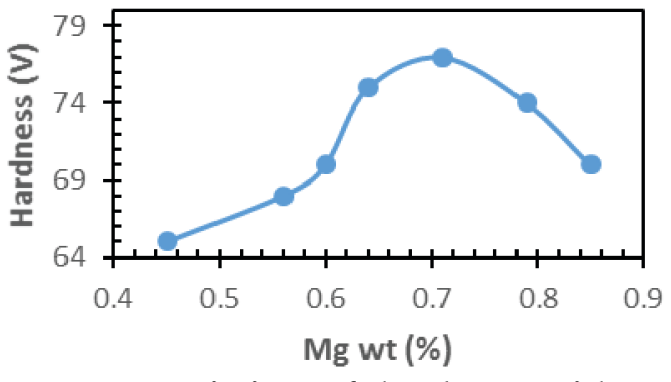

Figure 7 - Variation of hardness with $\mathrm{Mg}$ content

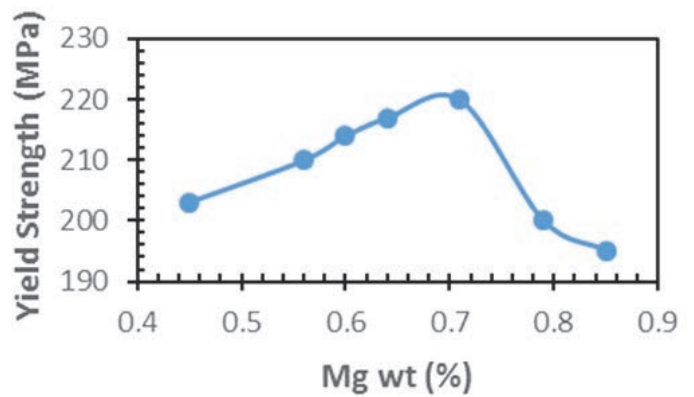

Figure 8 - Variation of yield strength with $\mathbf{M g}$ content

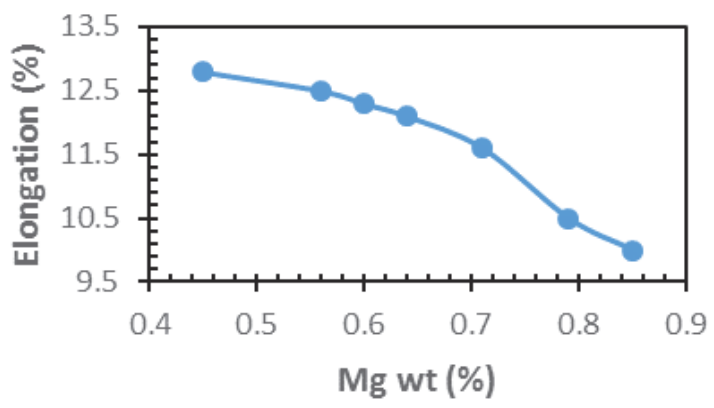

Figure 9 - Variation of percentage elongation with $\mathrm{Mg}$ content

\section{Conclusions}

Al 6063 samples with Mg contents between $0.45-0.85 \%$ showed hardness, yield strength and ductility (percentage elongation) in the ranges of $65-77 \mathrm{HV}, 195-220 \mathrm{MPa}$ and $10-13 \%$ respectively. Hardness and yield strength of the samples improved, and the ductility reduced when the $\mathrm{Mg}$ content was increased from $0.45 \%$ to $0.71 \%$. However, it was observed that the hardness and yield strength begin to decrease with a drastic reduction in elongation when the $\mathrm{Mg}$ content is increased beyond $0.78 \%$. It may be possible to change the above mentioned ranges of the properties by varying the contents of other alloying elements: $\mathrm{Si}, \mathrm{Mn}$ and $\mathrm{Cu}$.

\section{Acknowledgement}

The authors wish to express their deepest gratitude to Dr. Chandika Wickramatillake of Alumex (Pvt) Ltd for providing the samples for the tests along with the required technical information. Their thanks are extended to the Senate Research Council of the University of Moratuwa for the financial assistance provided and to Mr. A.A.M.T. Adikari of the Industrial Technology Institute of Sri Lanka for assisting in the analysis of the chemical compositions. Authors are also grateful to Mr. Vasantha Abegunaratna for helping to work with the induction furnace.

\section{References}

1. Yildirim, M., Ozyurek, D., "The Effects of $\mathrm{Mg}$ Amount on the Microstructure and Mechanical Properties of Al-Si-Mg alloys", J. Materials and Design, Vol. 51, 2013, pp. 767-774.

2. Jacobs, M. H., Talat Lecture 1204, Precipitation Hardening, Interdisciplinary Research Centre in Materials, The University of Birmingham, 1999, UK, pp. 25-30.

3. John, E. H., Aluminum: Properties and Physical Metallurgy, American Society for Metals, Metals Park, Ohio. 1984, pp.78-82

4. Rivas, A. L., Munoz, P., Camero, S. and OuinteroSayago, O., "Effect of the Microstructure on the Mechanical Properties and Surface Finish of an Extruded AA6063 Alloy", J. Advanced Material Science and Technology, Vol. 2., 1999, pp. 15-23.

5. Gupta, A. K., Lloyd, D. J., Court, S. A., "Precipitation Hardening in Al-Mg-Si Alloys with and without Excess Si", J. Materials Science and Engineering, A316, 2001, pp. 11-17.

6. Doan, L., Kiyomichi, C. N., Yoshitsugu, M., Sengo, K. and Yasuya, O., "Effects of Excess Mg and $\mathrm{Si}$ on the Isothermal Aging Behaviours in the Al-Mg2Si", J. Materials Transactions, The Japan Institute of Metals, Vol. 43, No. 6, 2002, pp. 13711380

7. Murayama, M., Hono, K., Miao, W. F. and Laughlin, D. E., "The Sequence of Precipitation in the Al-Mg-Si-Cu Alloy AA6111", J. Metallurgical and Materials Transactions, vol. 32A, 2001, pp 239246.

8. Shouxun, J., Wenchao, Y., Feng, G., Douglas, W., Zhongyun, F., "Effect of Iron on the Microstructure and Mechanical Property of Al$\mathrm{Mg}-\mathrm{Si}-\mathrm{Mn}$ and Al-Mg-Si Die Cast Alloys", J. Materials Science $\mathcal{E}$ Engineering, A564, 2013, pp.130-139.

9. Hernandez, M. F., Altamirano, T. A., Joes, M. H. and Rocha, E. R., "Effect of Nickel Addition on Microstructure and Mechanical Properties of Aluminum-Based Alloys", Materials science forum, vol 691, 2011, pp. 10-14 
10. Marioara, C. D., Andersen, S. J., Zandbergen, H. W. and Mestad, R. H. O. L, "The Influence of Alloy Composition on Precipitates of The Al-MgSi System", J. Metallurgical and Material Transactions, Vol 36A, 2005, pp. 691 -702.

11. De Silva, G. I. P. and Perera, W. C., "Improvement of the Mechanical Properties of Aluminum 6063 T5 Extrudates by Varying the Aging Condition Cost-Effectively", Proc. Research Symposium on Aadvancement of Science, South Asian Institute of Technology and Medicine (SAITM), Sri Lanka, 2012, pp.54-58.

12. Hussein, R. A, Abdullah, A. and Al-Belushi, K. R., "Influence of Aging Parameters on the Mechanical Properties of 6063 Aluminium Alloy", J. Materials Processing Technology, Vol. 102, 2000, pp. 234-240. 